\title{
English for Specific Purposes in Spanish Higher Education Settings: A Diagnostic Focus on Students' Preliminary Language Awareness, Attitudes and Expectations
}

\author{
Nuria Edo Marzá \\ English Studies Department, University Jaume I, Castellón, Spain \\ Email: nedo@ang.uji.es
}

\begin{abstract}
The present study tries to illustrate and analyse the initial or preliminary level of 'ESP awareness' that Spanish students from different scientific degrees have when first joining an ESP course. It also seeks to examine their motivations, expectations and attitudes towards the subject. By means of an anonymous questionnaire filled in during the first session of the course, Spanish students from Pharmacy, Biology and Environmental Sciences degrees reflected on the ESP teaching-learning process. The results obtained have revealed the (too) many aspects of specialised languages that students are not familiar with and the preliminary lack, in general, of basic English language knowledge from their disciplines. Presumably, as this and further studies on the topic will try to corroborate, this may be due to a nearly total lack of exposure to English language both in their everyday life and in their degrees, something illogical given the lingua franca status of this language nowadays and thus its importance in the transmission and spreading of scientific knowledge and results. On the basis of students' answers and views on the different aspects posed, a series of conclusions have been drawn and a broad course of action grounded on awareness-raising practices and students' attitudes and expectations has been suggested with the aim of overcoming the problems and inconsistencies brought to light by the questionnaires. Hence, this study is intended to be the first in a series analysing final performance and thus the evolution experienced.
\end{abstract}

Index Terms-English for Specific Purposes (ESP), preliminary language awareness, students' attitudes, expectations, teaching-learning process

\section{ENGLISH FOR SPECIFIC/SPECIAL PURPOSES IN HigheR EDUCATION}

Since the early 1960s, English for Specific Purposes (ESP) has progressively developed to become one of the most prominent areas of English as a Foreign Language (EFL) teaching nowadays. This importance is reflected in the increasing number of universities offering ESP subjects, modules, courses and MAs. It could be stated that ESP has increased over the decades as a result of market forces and a greater awareness amongst the academic and business communities that learners' needs and wants should be met wherever possible (Brunton, 2009), especially when related with professional necessities. In accordance with its practical, professionally-aimed scope, Dudley-Evans and St. John (1998) highlighted ESP as displaying a series of absolute and variable traits, such as the aforementioned fact of "being defined to meet specific needs on the part of the learners, of making use of underlying methodology and activities from the discipline it serves, and of being focused on the language appropriate to these activities in terms of grammar, lexis, register, study skills, discourse and genre" (p. 4). Moreover, as they point out, ESP is generally designed for intermediate or advanced students and most ESP courses assume some basic knowledge of the language systems. However, as this study tries to show, this desirable point of departure may not always be a reality among students and thus in the classroom setting.

Regarding some other more specific aspects of ESP that may be crucial in shaping students' perceptions of specific English, Mohan (1986) contends that ESP courses focus on preparing learners "for chosen communicative environments" (p. 15), whereas Lorenzo (2005) points out that ESP "concentrates more on language in context than on teaching grammar and language structures" (p. 1). Moreover, it has also often been contended that ESP is usually delivered to adult students with the perspective of a work-related setting. In this sense, Carter (1983) stated that an ESP course is concerned with turning learners into users of the language, something which, unfortunately, due to time or curriculum pressures, does not always happen.

From the aspects mentioned so far, what seems an undeniable fact is that any ESP course should be needs-driven, and should show an "emphasis on practical outcomes" (Dudley-Evan and St. John 1998, p. 1). Therefore, as Gatehouse (2001) and Graves (2000) contend, needs analysis is and always will be an important and fundamental part of ESP and its consideration will also include 'deficiency analysis', or assessment of the 'learning gap' (West, 1997) between target language use and current learner proficiencies. In fact, as Richards (2001) contends, the emergence of ESP (with its 
emphasis on needs analysis as a starting point in language programme design) had an impact on the development of current approaches to language curriculum development. Nowadays there is an increasing focus on looking at learners' subjective needs, "their self-knowledge, awareness of target situations, life goals, and instructional expectations" (Belcher, 2006, p. 136), which are the aspects this study has focused on in order to offer a reliable diagnostic portrait of the situation that may help to improve the ESP teaching-learning process as a whole and its perception on the part of students. Jiajing (2007) sums up these issues of ESP and ESP course design by stating that during the design of an ESP course, the top priority issue is to analyse the learners' specific needs followed by the analysis of other issues such as the determination of realistic goals and objectives, the integration of grammatical functions and the abilities required for future workplace communication, and assessment and evaluation. In this line, as Kaur (2007) concedes, when ESP learners are allowed to take some responsibility for their own learning and are invited to negotiate certain aspects of the course design, they feel more motivated to become more involved in their learning.

Deep reflection on and consideration of all the aspects mentioned above could help us to shed some light on what an ESP course is and thus on what is to be learnt and how, as well as on what kind of perception and expectations students may have in this respect. Therefore, the understanding of learners' purposes (Graham and Beardsley, 1986) and learning centredness (Carter, 1983; Hutchinson and Waters, 1987) must be considered integral parts of any ESP teachinglearning process. However, none of these considerations are effective if students themselves are not aware of what they need and expect, how they are going to get it and where they depart from, which makes it necessary for them to reflect deeply on the matter. This is necessary since research into language teaching has shown that there are considerable discrepancies between what teachers think students want and what the students actually want to do in the classroom (Brindley, 1984; Nunan, 1988; Peacock, 1998; Ramsden, 2003). Effectively bridging that gap is essential for learning.

All these aspects constitute the rationale of this study, which aims to be the first in a series intended at analysing what we have called 'ESP awareness', expectations and attitudes towards ESP on the part of Spanish university students ${ }^{1}$ at three different points in time: at the beginning of the subject (preliminary study, this particular one), half-way (progressive study, a prospective one) and end-of-subject (final study, a prospective one).

\section{Attitudinal IsSues AND LANGUAGE AwarenEss towards ESP SubJECTS}

In this very same line, and leaving to one side the particularities concerning his own research, González Ardeo (2003) describes university students' language attitudes as those feelings they express towards English or even towards the native speakers of this language. Despite the easily noticeable abstract and rather subjective nature of the concept, there is generalised agreement when it comes to acknowledging that the affective variable of attitude (together with others such as motivation or personality traits) has an influence on the level of proficiency achieved by learners (Gardner, 1980 and 1985; Oxford and Shearing, 1996).

On the other hand, language awareness (LA), as an area of research, became especially relevant from the 1990s onwards, when, as Svalberg states (2007), Language awareness in the classroom (James and Garrett, 1991) was published, the Association of Language Awareness (ALA) was founded in the UK, and the first issue of the journal Language Awareness was published (both events in 1992), or when Schmidt's (1990) paper on consciousness in language learning appeared. On its website, the ALA defines LA as 'explicit knowledge about language, and conscious perception and sensitivity in language learning, language teaching and language use'. Attitude seems thus to be also inherent in the very same notion of awareness and their interrelationship underlies, shapes and determines the competence and performance of most speakers of English as a foreign language. As the Association's webpage goes on to state, LA covers a wide spectrum of fields ranging from exploring the benefits that can be derived from developing a good knowledge about language, a conscious understanding of how languages work or of how people learn them and use them. In this line, LA is defined by Fairclough (1992) as 'conscious attention to properties of language and language use as an element of language education' and Donmall (1985) adds to this by describing it as involving 'a person's sensitivity to and conscious awareness of the nature of language and its role in human life' operating on three distinctive levels that students are very often not aware of, namely, the cognitive level (awareness of language patterns), the affective level (regarding the formation of attitudes) and the social level (involving the improvement of learners' effectiveness as communicators).

The focus on these aspects in this study originates in the author's belief that current ESP students in higher education settings in Spain tend to show a very poor initial or preliminary awareness of ESP, together with a weak understanding of what they are going to study and what for. This may be translated into having to depart in class from a poor preliminary knowledge of both general and specific language, from contradictory feelings and views about ESP, from scarcely reflective attitudes and from inaccurate perceptions of languages as a system and its object. It is our belief that a good linguistic knowledge, either general or specific, depends on a conscious understanding of the way languages work, that is, on being aware of the multifaceted nature of language, and on the attitude adopted towards it. It is crucial, we believe, for students to be aware of and have a good attitude towards any subject they may want to learn. In the specific case of awareness, Arndt, Harvey and Nuttall (2000) regard a focus on language awareness as bringing numerous benefits, among which we would highlight the fact of being more appreciative of the complexity and

\footnotetext{
${ }^{1}$ Enrolling in an ESP subject for the first time.
} 
sophistication of communicating through language, the fact of showing a better understanding of how English works and the fact that LA offers a productive and rewarding route for exploring the richness and complexity of language. Additionally, speakers are encouraged to draw inferential relationships between languages, which is one of the first steps in developing the intercultural communication skill, a fundamental aspect for developing the Critical Language Approach (CLA), which, despite surpassing the object and scope of this study, is also worth mentioning here.

Ideally, when first enrolling in an ESP subject, students should be preliminarily aware of their objectives, of the importance of ESP in their careers, of their attitude to language in general, and of their actual knowledge. This will favour the development of their specific awareness towards aspects such as the importance of genre, cohesion and coherence features, formal and informal style, rhetorical functions, context and vocabulary in ESP. Language awareness, as a way of language consciousness-raising, facilitates language acquisition, understanding and competence. A good, not merely intuitive, knowledge of students' language awareness may help improve students' performance in class and their attitude to the ESP subject, and should thus be critical in any course design. Accordingly, this study departs from the hypothesis that, in general, students in Spanish higher education contexts have a low preliminary awareness of ESP which is reflected - always in general - in their mostly non-participative attitude in class, in their scarce motivation, in the lack of reflective thinking about what they are studying and what for, and in the insecurity many of them show when the English language is involved in communicative situations. Therefore, it is important to know the preliminary level of specialised or specific language awareness students have when first joining an ESP class in order to be able to build the subject to meet students' expectations and needs. On the basis of this research and of the above-mentioned forthcoming studies on these very same aspects, we will attempt to compare preliminary, progressive and final results on awareness, attitude and expectations in order to try to demonstrate the importance of LA and the fact that, in every case, learners showing a higher level of awareness will tend to perform better, have higher expectations and gain more from the teaching-learning process. Consequently, we believe, this will turn into better and easier learning, more enjoyment in the teaching-learning process and better overall results in ESP subjects. Therefore, diagnostically determining, defining or measuring the attitudes, awareness and expectations of students may help us improve the way we teach, the way they (and also we, as lecturers ${ }^{2}$ ) learn and the way students will face professional situations involving the use of ESP.

\section{OBJECTIVES AND METHOD}

According to what has already been introduced in previous sections, our starting hypothesis (which has its origins in the author's previous teaching experience and impressions in the field of ESP in higher education settings) is that, in general, Spanish ESP students have a low language awareness when they first enrol in an ESP course. This is, in turn, translated into rather indeterminate expectations, a rather lethargic or apathetic initial attitude towards ESP (which may not disappear as the course proceeds) and a very basic knowledge and poor conscious perception of language as such. This presumed low preliminary language awareness may have negative effects on students' eagerness, interest in the subject and thus their final performance and results.

Hence, with the aim of obtaining and analysing data on students' preliminary ESP awareness, attitudes and expectations towards specialised language learning, a 19-item ${ }^{3}$ questionnaire made up of attitudinal, purely knowledge, self-reflection and interests-related questions purposefully designed for this study was created. By means of this anonymous questionnaire, filled in during the first session of the course, students from different scientific degrees namely, Pharmacy, Biology and Environmental Sciences - at Universitat de València ${ }^{4}$ (Spain) were expected to describe their preliminary thoughts on ESP in general, its main aspects, the teaching-learning process of speciality languages, their self-perception of their language level, their actual knowledge, their expectations and their needs as regards specialised languages. The students' answers and views on the different aspects posed were used to draw a series of conclusions as well as to suggest a number of proposals targeted at overcoming some of the problems and inconsistencies revealed by the questionnaires and at improving 'ESP awareness', teaching procedures and learning outcomes...'Hence, this study intends to be the first of a series in which the evolution experienced and final performance will also be analysed by means of the data gathered through similar questionnaires in the middle and at the end of the ESP course. These data have already been collected and are currently being processed and analysed for the aforementioned (forthcoming) comparative studies. Hence, the aim of the study was to analyse the LA and therefore the views, attitudes, knowledge (both real and alleged) and feelings that university students have about ESP subjects in Spanish higher education settings.

The ESP subjects analysed were either optional or free choice subjects, so that they could be assumed to hold a certain amount of interest for the students attending them. The age of the students participating in the research ranged from 18 to 28 years old (see Figure 1), with a clear predominance of the 21 and 22 year old students groups.

\footnotetext{
${ }^{2}$ As Ferro and Carvalho (2009) point out, the lecturer him/herself must show a good level of language awareness, since it is the knowledge that teachers have of the systems underlying language that enables them to teach effectively (Thornbury, 1997).

${ }^{3} 14$ main items and 5 sub-items.

${ }^{4}$ The author worked at Universitat de València (Valencia, Spain) during the academic years 2009-2010 and 2010-2011, which is when the data for this study were gathered. Currently, she works at Universitat Jaume I (Castellón, Spain), where she also teaches ESP.
} 


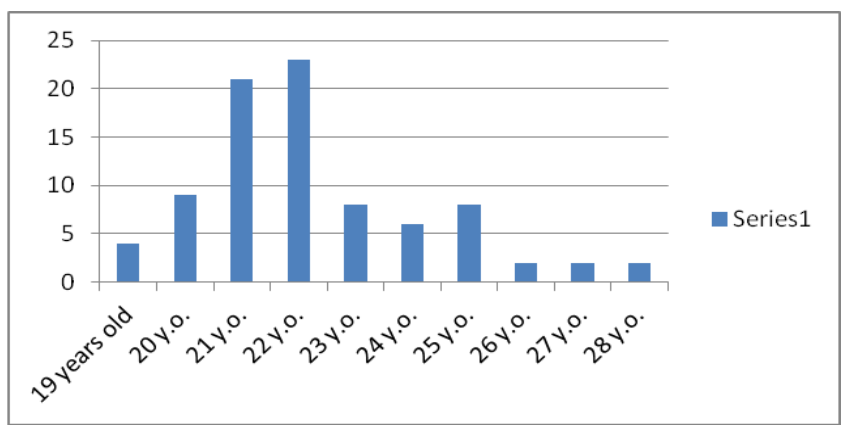

Figure 1: Age of the students participating in the research

Most of the students participating were in the second, third and fourth years of their degree courses. From all the students participating ${ }^{5}$ in the study, 85 in total, 63 were women and 22 were men. The total number of students enrolled in the two ESP subjects analysed was 153. The ESP subjects that the students taking part in the study were enrolled in were: Inglés para Ciencias de la Salud (English for Health Sciences) - whose students, a total of 69, belonged to the degree in Pharmacy - and Inglés Científico (Scientific English), whose students, a total of 16, came from the degrees in Biology (78\%) and Environmental Sciences (22\%).

The questionnaires were anonymous but students had to fill in their age, sex, degree and the year of their degree courses they were currently studying. The questions or items in the questionnaires were deliberately posed in Spanish and students could answer most of the questions - unless specifically asked not to do so - also in Spanish. The reason for this is that, since the questions were mostly intended at making students reflect on their views and feelings towards ESP, it was important to favour a global understanding on the part of students so that they knew exactly what they were being asked to do. The questionnaires were slightly different depending on the subject the students were enrolled in and, despite being asked to be concise in their answers, the majority of questions were open in order to allow students to express their feelings and impressions more freely, that is, no options were provided in most of the questions from the questionnaire in order not to condition their answers. The results then had to be - and in fact were - processed manually by the author of this paper.

The next section presents and succinctly comments on the results obtained in each of the questionnaire items. Section number 5 provides the concluding remarks that can be drawn from the results and opens the door to further research, courses of action and possible improvement measures so as to raise language awareness and foster more positive and eager attitudes towards ESP on the part of Spanish university students.

\section{RESUlts}

The results obtained from students' answers to the items in the questionnaire have been grouped here under the heading of their corresponding questionnaire item (translated into English for this paper).

QUESTION 1. In the field of English teaching, what do the abbreviations ESP or IFE (in Spanish) stand for?

None of the students knew the actual meaning of these acronyms; 82 students said they did not know their meaning or provided no answer at all, and there were just 3 attempts to figure it out:

1) ESP: ? ; IFE: Inglés específico para profesionales

2) ESP: español; IFE: International Foreign English

3) ESP: español; IFE: International ___ English

We are aware that this item related to the specific labelling of the area of knowledge under analysis and thus the results obtained have just an incidental value but can, however, be interpreted as a first indicator of the little preliminary awareness that students have as regards ESP issues.

QUESTION 2. How would you define your level of general English?

Two students considered that they had no level of general English at all or that it was very low; 29 students identified their level of general English as low-elementary; 10 of them considered it to be pre-intermediate; 32 thought it was an intermediate level; 11 of them considered it to be good/high/advanced and just one student considered him/herself to have a proficient command of English. Accordingly, just 12 out of 85 students (14\%) thought they had what could be considered a satisfactory level of general English.

QUESTION 3. How would you define your level of specific/specialised English (applied to your speciality domain)?

Ten students considered that they had no level at all or that they knew almost nothing about specialised English, whereas 55 of them considered it to be low or elementary. Four students thought they had a pre-intermediate level, 11 of them believed they had an intermediate level and just one student thought he/she had a good/high or advanced level. The remaining four did not indicate an established or conventionalised level of English but included statements such as:

\footnotetext{
${ }^{5}$ That is to say, attending the first class session of the subject.
} 
never worked on it; don't know; I normally understand the literature / bibliography I'm given in class; it's not that difficult because many words are nearly the same.

On comparing the results obtained in items 2 and 3 one may deduce that students tend to assume an extra difficulty in ESP subjects, probably due to a lack of familiarity with them, which may not benefit their attitude towards the subject and thus their performance in it. Results show that $36.5 \%$ of the students believed they had no level or a low level of general English, but $76.5 \%$ of them considered they knew no or very little ESP. The rest of the items in the questionnaire tried to elucidate whether this perception is grounded on a conscious self-awareness of ESP knowledge or simply on negative, unfounded perceptions arising from simple ignorance in relation to the subject.

QUESTION 4. Do you consider yourself capable of having a simple conversation in English about biology/environmental sciences OR pharmacy (choose depending on your degree) with a colleague for a couple of minutes?

Forty-four students considered themselves capable of maintaining a simple conversation in English about their speciality fields for couple of minutes, whereas 35 of them thought they would not be able to. Three students answered that it would depend on the level of specialisation, but they thought they would be able to manage; two of them stated that, in general, they could manage but that they were unsure about whether they would have enough vocabulary. Another one believed him/herself to be more or less capable of doing so but with a lot of difficulty. Figure 2 summarises these results by comparing them with the results obtained in the other skills.

QUESTION 4.1. What aspect of this conversation would you find the most difficult?

When students were asked about the specific difficulties they thought they would find in a specialised conversation, the answers were varied and, according to the responses obtained, have been classified into four main aspects: 1) speaking/producing; 2) listening/understanding; 3) specific vocabulary/terminology; and 4) others (see Table 1). The specific difficulties enumerated and the number of students mentioning them have been grouped (and translated) under their corresponding general aspect, as Table 1 shows:

TABLE 1.

ASPECTS CONSIDERED THE MOST PROBLEMATIC IN A SPECIALISED CONVERSATION

\begin{tabular}{|c|c|c|c|}
\hline Speaking / producing & $\begin{array}{l}\text { Listening / } \\
\text { underst. }\end{array}$ & $\begin{array}{l}\text { Specific } \\
\text { vocab. / } \\
\text { terminology }\end{array}$ & $\begin{array}{l}\text { OTHERS } \\
\text { (miscellaneous category) }\end{array}$ \\
\hline $\begin{array}{l}\text { - Speaking / producing in } \\
\text { general (7) } \\
\text { - Answering (4) } \\
\text { - Fluency (5) } \\
\text { - Pronunciation (4) }\end{array}$ & 11 & 40 & $\begin{array}{l}\text { - Grammar (3) } \\
\text { - All of them (2) } \\
\text { - Don't know (1) } \\
\text { - Set expressions (1) } \\
\text { - Verbs (1) } \\
\text { - Not translating directly / literally } \\
\text { from Spanish (1) } \\
\text { - Talking in a scientific way (1) } \\
\text { - Fluency (1) } \\
\text { - Connecting sentences correctly (1) } \\
\text { - None (1) } \\
\text { - Improvising (1) }\end{array}$ \\
\hline
\end{tabular}

It is significant to observe how students assign a central role to learning specific vocabulary/terminology: 40 out of 85 considered it a key aspect that would turn out to be the biggest problem for them in a specialised conversation. Broadly speaking, then, $23 \%$ of the students considered speaking/producing in general to be the most difficult part, $13 \%$ considered listening/understanding to be the most problematic aspect, $47 \%$ of them regarded specific vocabulary/terminology as the biggest hurdle, and the remaining 17\% mentioned other kinds of difficulties.

QUESTION 5. Do you consider yourself capable of understanding a brief presentation in English (for instance, at a conference) about some basic aspect related to biology/environmental sciences OR pharmacy (choose depending on your degree)?

Forty-three students thought they would be capable of understanding a brief presentation in English about some basic aspect related to their speciality domains, whereas 24 thought they would not be able to. Another student thought that without the aid of a PowerPoint presentation he/she would not be able to; four students believed that it would depend on the pace and the accent, and 10 of them considered that they would be able to grasp just the main idea. Another two reported that it would depend on the level of technicality and specialisation. Finally, another one signalled that if the person was not a native speaker, he/she could probably understand him/her better. Figure 2 summarises these results by comparing them with the results obtained in the other skills.

QUESTION 5.1. What aspect of this presentation would you find the most difficult?

When they were asked about the most difficult part of this presentation, 43 of the students mentioned that specific vocabulary was the aspect that they would find most problematic, whereas 29 of them mentioned listening/understanding as being the most challenging issue for them. Of these 29 , listening/understanding in general was mentioned by five of them, whereas 14 mentioned specific aspects of it, such as the speed/pace of the speaker. Another 10 considered pronunciation/accent to be the most difficult aspect. Table 2 summarises the results obtained in this respect: 
TABLE 2.

ASPECTS CONSIDERED THE MOST PROBLEMATIC FOR UNDERSTANDING A SPECIALISED PRESENTATION.

\begin{tabular}{|l|l|l|}
\hline $\begin{array}{l}\text { Specific } \\
\text { vocab. }\end{array}$ & Listening / understanding & OTHERS (miscellaneous category) \\
\hline 43 & $\begin{array}{l}\text { - Listening / understanding in } \\
\text { general (5) }\end{array}$ & $\begin{array}{l}\text { - To follow 100\% of the presentation (1) } \\
\text { - Everything (7) }\end{array}$ \\
& $\begin{array}{l}\text { - Speed / pace of the speaker (15) } \\
\text { - Pronunciation / accent (10) }\end{array}$ & $\begin{array}{l}\text { - Words that are not similar to Spanish (1) } \\
\text { - It would depend on the topic (whether I know } \\
\text { something about it or not) (1) }\end{array}$ \\
\hline
\end{tabular}

QUESTION 6. Do you consider yourself capable of writing a brief article in English entitled 'The environment'/ 'Pills and syrups' (choose depending on your degree)?

Fifty of the students considered themselves capable of writing a brief article on the topics suggested, whereas 30 of them answered that they would not be able to do so. Another two pointed out that they would do it only with a dictionary at hand, whereas three of them responded that they would know what to talk about, but they could not write an article about it. Figure 2 summarises these results by comparing them with the results obtained in the other skills.

QUESTION 6.1. What would you talk about?

In this question, the 30 students (35\% of the participants) who answered NO in question number 6 did not give an answer. This item was intended to show whether the students, most of whom were in the last years of their degrees, were familiar with some of the most basic words from their respective speciality fields. It would have been logical to think that they were familiar with these terms, but the results - with 30 students not answering the question - seem to show the opposite.

In this question, some students answered by simply translating the article titles, whereas others enumerated issues related to the words or different aspects of the topic.

Hence, those who answered that they would be able to write about the aspects proposed, provided the answers summarised and translated into English in Table 3:

TABLE 3.

TOPIC WORDS OR ISSUES AS IDENTIFIED BY STUDENTS (AND TRANSLATED FOR THIS STUDY).

\begin{tabular}{|l|l|l|l|}
\hline $\begin{array}{l}\text { 'the environment' (what those answering YES, I } \\
\text { COULD WRITE ABOUT IT said) }\end{array}$ & \multicolumn{1}{|l|}{ 'pills and syrups' (what those answering YES, } \\
I COULD WRITE ABOUT IT said)
\end{tabular}

QUESTION 6.2. What aspect would you find the most difficult when writing this article?

This question was also left blank by many students (probably the same ones who answered NO in question number 6). Once again, most of them (46 students) considered specific vocabulary to be the most difficult aspect - specifically the lack of specific vocabulary or the difficulty inherent in the terms to be used. Table 4 summarises the results obtained in this item:

TABLE 4.

ASPECTS CONSIDERED THE MOST PROBLEMATIC WHEN WRITING A SPECIALISED ARTICLE.

\begin{tabular}{|c|c|l|}
\hline $\begin{array}{l}\text { Specific } \\
\text { vocabulary } \\
\text { (lack of SV or } \\
\text { difficult SV) }\end{array}$ & $\begin{array}{l}\text { Grammar } \\
\text { (mainly } \\
\text { tenses) }\end{array}$ & OTHERS (miscellaneous category) \\
\hline 46 & 4 & $\begin{array}{l}\text { - Linking the main ideas in a coherent way (connectors) (1) } \\
\text { - Providing a coherent structure for the information (1) } \\
\text { - Providing the text as a whole with cohesion and continuity (1) } \\
\text { - All (4) } \\
\text { - Interrelating the different parts of the text (1) } \\
\text { - None (2) } \\
\text { - Writing a formal text (1) } \\
\text { - The approach of the text (1) }\end{array}$ \\
\hline
\end{tabular}

QUESTION 7. Do you consider yourself capable of understanding (as a whole) a specialised article of average difficulty in English published in some biology/environmental sciences OR pharmacy (choose depending on your degree) journal? 
Fifty-one students considered themselves capable of doing so, whereas 12 answered that they would not be able to do it. Seventeen students stated that they would be able to understand it in general, that is, they would be capable of extracting the main idea; another two conditioned the success of the task to the fact of having enough time and a dictionary, and another two believed the topic would be a key aspect for determining whether they would be capable or not. Finally, another one reported that the greatest difficulty was likely to be that there would be too many words that he/she would not understand. Figure 2 summarises these results by comparing them with the results obtained in the other skills.

QUESTION 7.1. What aspect would you find the most difficult one to understand the article?

Once again, most of the students (70) named specific vocabulary (lack of/difficulty in) as the main hurdle preventing them from understanding the article. Table 5 summarises the results obtained in this respect:

TABLE 5.

ASPECTS CONSIDERED THE MOST PROBLEMATIC FOR UNDERSTANDING A WRITTEN SPECIALISED ARTICLE.
\begin{tabular}{|l|l|}
\hline $\begin{array}{l}\text { Specific vocabulary (SV) } \\
\text { (lack of SV or difficult SV) }\end{array}$ & OTHERS (miscellaneous category) \\
\hline 70 & $\begin{array}{l}\text { Verbs and adverbs (3) } \\
\text { However, many of them indicate that with a } \\
\text { dictionary this would not be a problem. }\end{array}$ \\
& $\begin{array}{l}\text { Structures (understanding whole sentences) (9) } \\
\text { Everything (2) } \\
\text { None (1) }\end{array}$ \\
\hline
\end{tabular}

Finally, Figure 2 summarises and compares the results obtained in items 4, 5, 6 and 7 graphically.

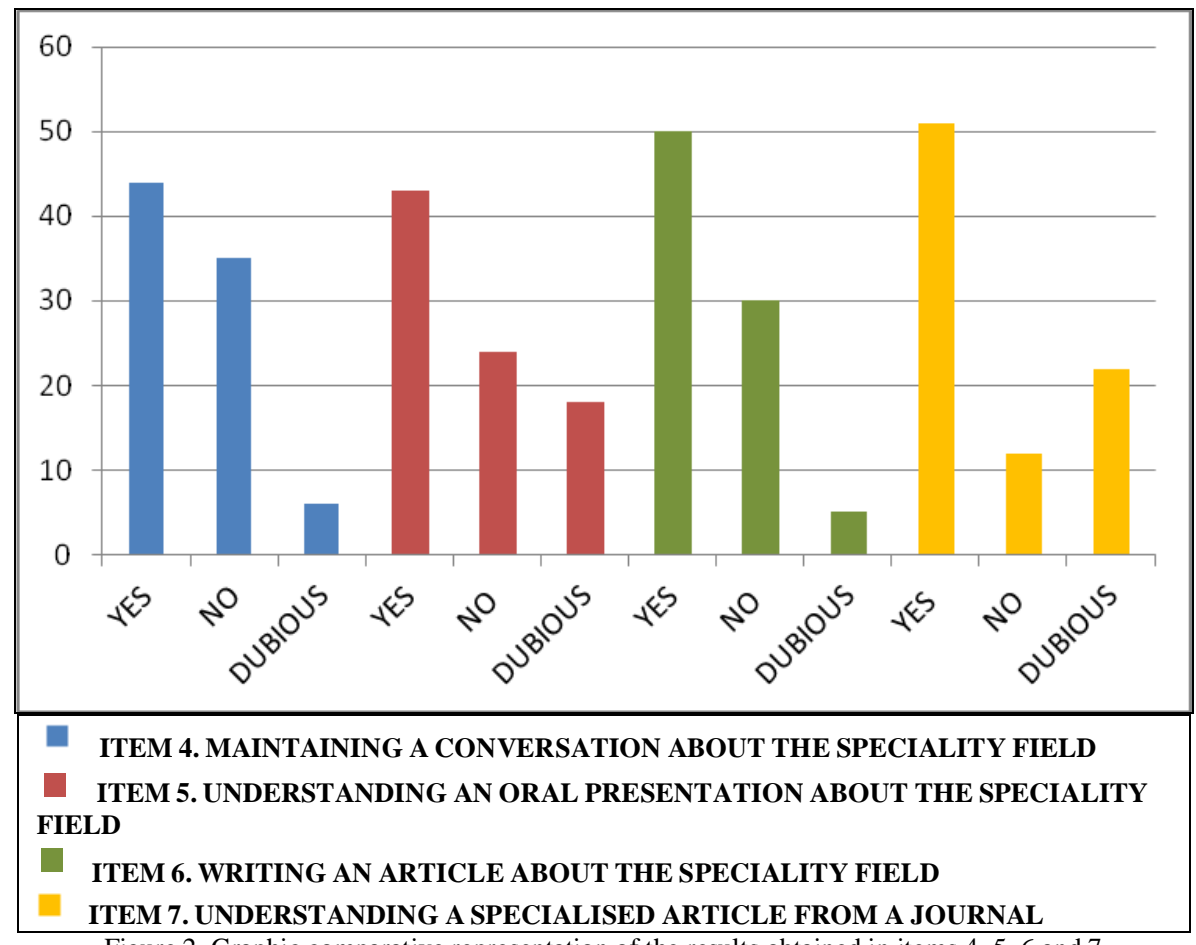

Figure 2. Graphic comparative representation of the results obtained in items 4, 5, 6 and 7

According to the results obtained in these items, on the one hand, the aspects seeming to cause more uncertainty or dubitation among students (category 'dubious': students not sure about whether they would be able to manage in the situations mentioned (referring to a specific skill)) are those related to the listening one (understanding conference-type presentations) and to the reading skill (understanding journal research articles). This is probably due to the fact that the familiarity and exposure of students to these genres is scarce, despite the importance they have in the academic world and despite the fact that at least last-year students should ideally already be familiar with them.

On the other hand, the understanding of journal research articles is also the aspect in which most students feel capable of managing ('yes' category), followed closely by that of being able to write an article about the speciality field. In general, it seems that students feel more confident in those aspects which allow for careful thinking and consultation of external resources (normally dictionaries, internet sites or experts), that is, in aspects that do not call for such rapid action and which, therefore, do not imply immediate interaction, response or understanding.

Finally, the 'no' category (I would not be capable of doing so) reaches its highest rates in Figure 2, with the production skills: speaking (maintaining a conversation about the speciality field) and writing skills (writing an article about the speciality field) are the ones students feel less confident in. When it comes to producing, students tend to get 
easily discouraged since, as they themselves point out, they lack the vocabulary and structures needed to express themselves accurately and they do not feel fluent enough, among many other aspects.

QUESTION 8. Let's set out from the fact that it is neither possible nor desirable but imagine that you could develop only one of the following skills for managing in your future job - which one would it be? Why?

- The ability to talk about my speciality field (speaking skill)

- The ability to understand anybody talking about my speciality field (listening skill)

- The ability to understand anybody writing about my speciality field (reading skill)

- The ability to write about my speciality field (writing skill)

In this item, $45 \%$ of the students did not answer the 'why' question. Regarding students' 'preferred' skill (or the one they regarded as the most important), 26 students chose the ability to talk about their speciality fields (speaking skill) as the one they would like to develop if they had to choose. Among the reasons put forward for doing so, students mentioned that if they can speak it means that they understand, that oral communication is crucial in their speciality areas, that it is the most useful skill, that it includes the other three, that it is important for feeling comfortable when going abroad or dealing with foreigners, that they would need it to share information with other colleagues and that it is necessary to study abroad.

The ability to understand anybody talking about their speciality fields (listening skill) was the preferred one for another 26 students, who commented that with this skill new concepts can be learnt easily, you can work in any part of the world, you can successfully manage and be competitive in your profession and you can have and/or understand other resources and sources of information and research.

Somewhat surprisingly, another 26 students regarded the ability to understand anybody writing about their speciality fields (reading skill) as the most important skill. The reasons put forward are that with this skill they would be able to do their university assignments more easily, they could read research papers in English and they would be able to access updated academic information.

Finally, apart from the triple tie in terms of number of students in the three preceding skills (26 in each), the ability to write about their speciality fields (writing skill) was considered to be the most important by a minority of students (seven). Those having chosen this skill conceded that if they can write correctly then they would most probably be able to communicate orally as well. It is, however, worth noting that the skill most students feel more comfortable with or proficient in is also the one they tend to consider the 'least' important for their careers, this apparently showing that students tend to grant more value to those aspects they find more difficulty in.

QUESTION 9. Do you consider that English is important in your training as a biologist/environmental scientist OR pharmacist (choose depending on your degree)? Why?

Only three students considered English non-relevant for their training and professional career, arguing that their professional objectives are not related with English and that it would all depend on the kind of work to be developed afterwards.

However, those who regarded English as important (82 students) mentioned the following reasons for doing so (even though not everybody answered the 'why' question either):

- It is fundamental for working abroad and/or in multinationals

- Scientific research is mainly conducted abroad and the lingua franca for communicating abroad is English

- English is very useful for any kind of job as it 'opens doors'

- Scientific knowledge transmission is mainly achieved through English; almost 'everything' is written in English

- English is the basic language of science; it is useful for attending conferences and for working with specialised literature; English is necessary to understand articles and research papers

- English is important in every single discipline and in life in general

- English is crucial to be able to deal with foreign patients/clients and colleagues in general

- English is the most important and widely spoken language

Most of the students provided more than one reason, so the answers/results in this item were considered mainly from a qualitative perspective and have been grouped into the broad categories above. However, as is subsequently analysed, the results obtained in this question actually seem to contradict those obtained and shown in item 14, which reflects a lack of coherent, holistic thinking on the part of students.

QUESTION 10. What do you expect / would you like to learn in this subject?

Most of the students (47) expected to learn specific vocabulary or terminology, 10 students expected to learn to communicate and understand texts in English and seven of them expected to 'refresh' their knowledge of English. Among the other things students expected to learn in the subject we find:

- learning to speak fluently, acquire fluency

- improving their oral and writing level and their understanding of English

- learning expressions

- widening their knowledge

- learning phonetics

- passing the subject without the need to make a great effort 
- understanding and making themselves understood

- learning the capacity to manage in English-speaking environments

In this question, some students also provided more than one response, so the answers in this case have been considered mainly from a qualitative perspective. The most outstanding result here is probably the fact that, in many cases, students seem to expect to learn the same things they would allegedly expect to learn in a general English course except for the specific vocabulary. Once again, they tend to associate ESP with learning just vocabulary/terminology.

QUESTION 11. Could you translate the following words into English?

Scientific English students only:

Biólogo/a ${ }^{6}$

English for Health Sciences students only:

Farmaceútico/a (sust) ; Farmacia ; Biológico/a

The aim of this question was similar to the one in question 6.1, that is, to assess students' basic, preliminary knowledge of ESP in their respective fields of knowledge. Some of the attempts found in the questionnaires were incorrect forms or even invented instances, thus showing what could be called a negative or bold creativity on the part of students as shown, for instance, in invented lexical units such as boticarious*, boticary*, pharceuty* or pharmacien*.

It is surprising that some invented and obviously incorrect units were believed to be right by more than one student, thus presenting more than one instance among the results. Table 6 shows the answers obtained. In this respect, the dotted line and its corresponding number at the bottom of each column show the number of students who left the question blank, while the asterisks indicate that the answer provided is not correct.

TABLE 6.

TRANSLATION OF THE UNITS PROVIDED BY STUDENTS.

\begin{tabular}{|c|c|c|}
\hline FARMACEUTICO (SUST) & FARMACIA & FARMACOLOGICO \\
\hline Pharmacist (20) & Pharmacy (36) & Pharmacological (5) \\
\hline Chemist (9) & Chemestry $^{\star}$ (2) & Pharmacologic* (22) \\
\hline 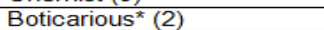 & Apotheke $^{*}(1)$ & Pharmacology* (3) \\
\hline Boticary* (1) & Chemist* $^{*}(1)$ & Chemyst* $^{*}(1)$ \\
\hline Pharmaciest* (2) & Apoteke $^{*}(2)$ & Pharmacologist* (5) \\
\hline Pharceuty* (1) & Drugstore (1) & Farmacology $y^{\star}(2)$ \\
\hline Chemistry $^{*}(6)$ & 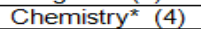 & Pharmacologyc* (5) \\
\hline Quemist $^{*}$ (1) & 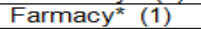 & Farmacological $^{*}(1)$ \\
\hline Farmacist* (1) & Chemist $^{*}(7)$ & Pharmaceutical $^{*}$ (1) \\
\hline Pharmaceutyc $^{\star}(1)$ & Chemistry $^{*}$ (1) & Chemistry $^{*}(2)$ \\
\hline Pharmaceutic* (2) & Quemistry* (1) & Pharmacology* (4) \\
\hline Chemis $^{*}(1)$ & Pharmacie $^{*}(2)$ & Pharmacologyst* (1) \\
\hline Chemist officer* (1) & Pharmy $^{*}(1)$ & Pharmacologuc* (1) \\
\hline Quemister* (4) & -... (9) & $(16)$ \\
\hline \multicolumn{3}{|l|}{ Chemistical $^{*}(1)$} \\
\hline \multicolumn{3}{|l|}{ Pharmacyst* (3) } \\
\hline \multicolumn{3}{|l|}{ Pharmacien* (1) } \\
\hline \multicolumn{3}{|l|}{ (12) } \\
\hline BIOLOGO & BIOLOGIA & BIOLOGICO \\
\hline Biologist (9) & Biology (16) & Biological (6) \\
\hline 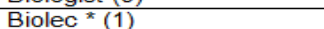 & & 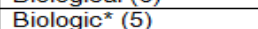 \\
\hline Biologyst" (1) & & \begin{tabular}{|l} 
Biologycal $^{*}(2)$ \\
\end{tabular} \\
\hline$-(5)$ & & $-(3)$ \\
\hline
\end{tabular}

QUESTION 12. From the following excerpts, which one is more likely to belong to a research article published in a prestigious journal?

A. With the exception of electrons, the particles which have been accelerate to high energies for machines such as cyclotrons or Van de Graaff generators have not be directly used therapeutical.

B. Except for electrons, the particles which have been accelerated to high energies by machines such as cyclotrons or Van de Graaff generators have not been directly used therapeutically.

C. I won't talk about electrons but my successful research has shown that the particles which have been accelerated to high energies by machines such as cyclotrons or Van de Graaff generators have not been directly used therapeutically

D. Forget about electrons; the rest of the particles which have been speeded up to high energies by machines such as cyclotrons or Van de Graaff generators haven't been directly used therapeutically.

Option B was the only correct (original) option in this question. However, 30 students believed option A was the correct one, 12 believed it was $\mathrm{C}$ and six believed it was $\mathrm{D}$. The remaining 47 students chose the correct option (B). The students who chose option A were not aware of basic English grammar rules, namely the formation of the present perfect tense, among other things. The students who chose option $\mathrm{C}$ showed no awareness of the basic rhetorical and stylistic features characterising academic research articles such as avoiding the use of contracted forms, the necessary use of hedging or the necessary level of formality required in the genre, among others. Option D also lacks adequate management of formality and scientific discourse conventions. Therefore, more than $50 \%$ of the students participating in the survey showed no familiarity or awareness with the basics of scientific discourse and with the prototypical academic genre, the research article. Students acknowledge the importance of terminology in ESP but show no

\footnotetext{
6 Biólogo: biologist; Biología: biology; Biológico: biological Farmacéutico: pharmacist/chemist; Farmacia: pharmacy; Farmacológico: pharmacological
} 
awareness of academic discourse and academic genres, and this is probably due to long-term acquired teaching-learning practices which should be improved and go beyond (or focus on aspects other than) the mere acquisition of grammar and vocabulary.

QUESTION 13. You would feel especially disappointed if, in this subject, you were not taught... (choose the answer you consider to be the most important for you)

A. The main linguistic and terminological patterns characterising speciality English.

B. The attitude I should have towards speciality English and its importance for my professional future.

C. How to communicate in an effective way in a specialised context.

The results in this item, based on Donmall's (1985) distinctive levels of LA (option A corresponds to the cognitive level, option B with the affective level and option $\mathrm{C}$ with the social level), show a clear predominance of cognitive and social levels/aspects among students' preferences. Forty-one students chose option A, 44 students chose option C and none of them signalled option B as the most important aspect. This can be interpreted as a general disregard of reflective or attitudinal purposes on the part of students, probably stemming from the kind of quantitative assessment students are used to and hence implicitly assume in their learning. Students' answers seem to indicate that they wish to focus their efforts on being taught those aspects which are more traditionally associated with the learning of languages (that is, mostly, learning language rules and vocabulary) and that are therefore more easily transmittable, demonstrable and assessable and which, consequently, they also perceive as more useful and practical.

QUESTION 14. I consider my general attitude towards this subject as:

A. Indifferent: it is a mere requirement to obtain more credits and thus to get my degree.

B. I don't like English very much/I'm not good at English so I don't think I'm going to enjoy the subject.

C. Highly positive: I'm looking forward to starting and learning a lot.

Finally, Figure 3 shows the alleged attitude of the students taking part in the study towards the subject: 43 students manifested their indifference towards the subject (option A), 37 foresaw their lack of enjoyment in the subject by choosing option B and just 15 students claimed to have a highly positive attitude towards the subject. By comparing the results in items 9 and 14, it may be observed that students seem to be aware of the importance of English in their speciality fields, but their attitude towards learning it does not reflect this supposed importance.

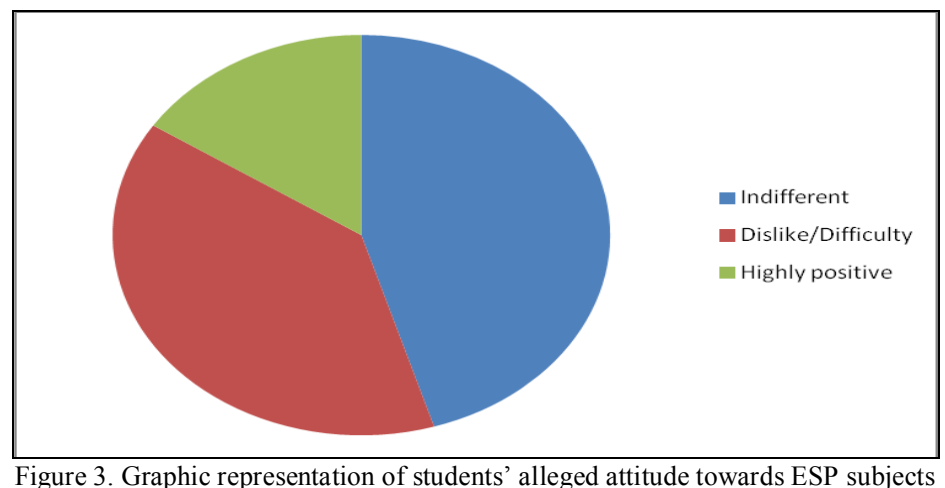

Section 5 comments on these results and draws conclusions from them. The author also discusses the most remarkable aspects to be considered and tries to suggest some possible course of action that can be employed both to prevent disappointing attitudes and results in the ESP classroom and to improve them.

\section{DisCUSSION AND CONCLUSIONS}

On the basis of students' answers and views on the different items posed, it may first be stated that the results revealed by purely 'knowledge-testing' questions were rather discouraging. Despite the fact that most of the students were in the second, third and fourth years of their degrees, only $40 \%$ of the basic vocabulary answers provided by students in question 11 were correct, which reveals a surprising ignorance of basic terminological units despite considering this to be a central aspect in ESP learning. Something similar was found in question 6.1 , in which $35 \%$ of the students answering the questionnaire were unable to say what topics they would write on if asked about 'the environment' and 'pills and syrups'. In the same way, students' scarce familiarity with typical academic genres and discourse - what should be, in our opinion, a critical part of any ESP course - was also displayed by the fact that more than half of the participants in the survey were not able to recognise a proper academic style. This shortcoming could probably be extrapolated to the greater context of students' respective degrees and should be put to rights by trying to make students familiar from the very beginning with research genres and discourse regardless of the specific subject being dealt with. University students in general need to read, especially in the last years of their degrees, and students would undoubtedly benefit from reading and getting used to research articles in English as the lingua franca of knowledge transmission. 
Additionally, the scarce knowledge of metalinguistic knowledge on the part of students that was detected in the study also complicates the teaching of ESP. Many students are not familiar with basic linguistic labels such as noun, verb and adjective and are unable to distinguish between such categories, which complicates the teaching of any foreign language and therefore the learning process itself.

The perception many students have with respect to their level of English is not promising either. The perceived-level results obtained seem to show the low preliminary ESP awareness students have and believe they have. Some of them do not seem to realise the necessary relationship between general and specific English for specialised discourse production. At the same time, however, students also tend to extrapolate their expectations as regards general English learning to their expectations for ESP learning. The aforementioned necessary relationship between the two but also the particularities of ESP should thus be emphasized and made clear from the very beginning so that the students get a coherent, integrated view of the subject.

Nonetheless, the fact that more than $96 \%$ of the students taking part in the survey considered English to be crucial for their professional future (question 9) is positive for the subject, even when just $14 \%$ of them believed they have a good level of both general and specialised English. The general feeling seems to be that students believe they have the elementary productive and receptive skills which would allow them to grasp the essence of English specialised discourse (both oral and written), but their level of confidence in their ESP knowledge seems very limited and does not favour the feeling of confidence that is so necessary when interacting in a foreign language. Moreover, students are aware of the importance of English in their careers but the majority of them do not undertake the task of learning ESP with eagerness or expectancy (results for item 14). Students' positive attitude towards ESP for their professional career does not coincide with their negative or apathetic attitude towards making the effort of learning ESP and thus towards the subject itself (as results for item 14 show).

Regarding expectations, it is also highly revealing to note the importance granted to terminological knowledge by students: nearly $50 \%$ of them considered it the key/central aspect to learn but also one of the most difficult aspects in ESP. In general, the students taking part in this research seem to be interested in learning ESP because they expect to be able to understand and make themselves understood in international scientific-technical or professional contexts. They also know it will be important in their careers, especially if they intend to work abroad. In general, they expect to obtain a preparation that enables them to cope professionally in a foreign language. These results contrast again, however, with the kind of results obtained in question 14, in which over $82 \%$ of the students expressed their indifference or dislike for the subject. Once more, this contradictory position highlights a situation in which further work and research are needed: students are aware of the importance of ESP for their professional careers but are more reluctant to make the effort that ESP learning necessarily implies. Lecturers should try to make ESP learning enjoyable and fruitful so that both contradictory views converge in an overall positive attitude.

When asked about more specific aspects of their specialised linguistic knowledge and skills, $51 \%$ of the students considered themselves capable of holding a short conversation about their areas of specialisation despite the low level of English most of them believe they have and the low participation they show in oral in-class activities. Fifty per cent considered themselves capable of understanding a brief presentation on their specialisation areas, while 58\% considered themselves capable of writing a brief article about their specialisation fields in English and $60 \%$ of the students considered themselves capable of understanding an 'easy' research paper in English. A simple interpretation of these results could be that students generally regard speaking and listening as the most difficult and demanding skills, whereas reading and writing are considered slightly more accessible or easier. As regards the importance granted by the students to the different skills, it is interesting to observe the triple tie obtained in the speaking, listening and reading skills (26\% of the students considered each of these skills as the most important ones for their careers), whereas the writing skill seems to be considered the least important by students (7\%). In general, among the aspects that students tend to consider as being more difficult for producing (speaking and writing) specialised English language we find, above all, the level of specialisation required, and the quality and quantity of the vocabulary that must be possessed in order to express oneself correctly and accurately. On the other hand, among the aspects considered to be more difficult in receptive skills (reading and listening) we find: the pace, accent and speed of the discourse, and also the level of technicality and specialisation needed in the structures and the vocabulary.

Finally, it is interesting to notice the rather simplistic view that some students have of ESP: some of them believe it to be an aspect of the general English language that can be effectively managed simply with the help of a dictionary. They do not seem very aware of the conventions, specificities and idiosyncrasies that ESP implies beyond terminology acquisition, that is, at a discourse level or from a rhetorical perspective. In the questionnaires nobody mentioned the importance of structural aspects or the importance of formality, stylistic and discourse features such as precision, objectivity, concision, hedging or the lack of ambiguity, among many others. Hardly anyone noted the importance of cohesion and coherence either. Moreover, typical academic discourse was identified by a scarce 55\% of the students, the remaining $45 \%$ being unable to recognise an excerpt from an academic article. Accordingly, many students seem to show no familiarity with or interest in those aspects of ESP that go beyond the acquisition of terminology or communicative strategies (normally associated with oral communication). In the same way, as the results obtained in item 13 seem to corroborate, students are very much aware of the importance of the cognitive and the social levels of language awareness but the affective level was disregarded by all the students. Obviously, this does not mean that they 
grant no importance at all to this aspect, since they were forced to choose just one of the options, but the fact that nobody chose it as the first option is indicative of one of the aspects traditionally (and generally) neglected in the Spanish ESP classroom, which should thus be enhanced and dealt with, namely, attitude training, and not just content training.

From the results, it seems obvious that students need and expect to see a practical applicability in everything they learn, and that professional English is no exception. Most students of ESP subjects acknowledge the importance of English in their professional careers, although results show that something is going wrong in the way lecturers and students in Spain start with and approach the teaching and learning process of both general English and ESP. Language awareness and language development are highly determined by the attitude consciously or unconsciously adopted by the students during secondary education and even at primary school. Fostering a positive attitude and making the students consciously and successfully acquire the essentials of the English language will be crucial for attaining success in subsequent stages. Furthermore, lecturers have to make students overcome the rather simplistic view of the kind of knowledge to be acquired in ESP classes and make them understand the rich complexity underlying any language. ESP goes beyond the acquisition of new vocabulary and makes it necessary to become familiar with many aspects of academic writing, genre conventions and discourse conventions - something students need to be aware of. Therefore, apart from the facts and factors just mentioned, awareness is not simply a matter of students. As Miller states (2007), lecturers have to be more aware of their audience and perhaps make more allowances in the presentation of information to ensure that it is accessible to the L2 students. Interest and attitude are fundamental for learning and improving and lecturers themselves are a central element to foster this. Accordingly, task-based exercises in which students envisage the aforementioned practical applicability should be devised and implemented for the ESP student. Otherwise, disappointment quickly appears in the ESP classroom even in such early stages of the subject as the one analysed in this study. If students have had a bad or disappointing experience in their learning of English, they will probably tend to associate any other English subject with that disappointing experience. Diagnostic surveys or questionnaires that help us know our students' expectations and attitudes towards language better are always an interesting and easy method to improve subject design, syllabuses and lectures from scratch.

It is also worth mentioning that the kind of exposure students have to the English language seems too/very limited, in general, in Spanish higher education settings. In fact, there is an almost total lack of exposure to English language and to academic genres on the part of students both in their everyday life and in their degrees. As the results obtained in this study seem to show, ESP should not be studied as an artificial, watertight subject having nothing to do with other degree subjects or with real world careers. It would be vital for lecturers from any subject to acknowledge and highlight the importance of English as the language of knowledge transmission and as the Lingua Franca of the current world. It is also essential for students to become familiar with specialised literature (and academic style and genres) written in English from the very first years of their degrees, in a progressive but continuous way. This would imply, however, that many lecturers would also have to make the effort of updating their knowledge of specialised English, yet the rewards would surely outweigh the additional and considerable effort of doing so.

What seems clear is that attention and awareness facilitate learning. Students seem to be aware of the fact that if they are to become complete, successful professionals, they will need English. However, they are also rather pessimistic when it comes to expressing their views on their command of English. Unfortunately, as this study shows, it is, in general, true that many students in Spanish higher education settings present serious deficiencies in their command of English in general, a very low preliminary awareness of ESP and rather negative attitudes towards ESP subjects, which contrast with many of their expectations. A conscious, well-grounded detection and analysis of this kind of factors negatively affecting ESP teaching and learning will determine the possibility of working on them and overcoming them, which could in turn result in increased language awareness and a positive attitude towards ESP, which are the cornerstones for effective ESP learning.

\section{REFERENCES}

[1] Arndt, V., P. Harvey \& J. Nuttal. (2000). Alive to language. Cambridge: CUP.

[2] Belcher, D. (2006). English for specific purposes: Teaching to perceived needs and imagined futures in worlds of work, study and everyday life. TESOL Quarterly 40.1, 133-156.

[3] Brindley, G. P. (1984). Needs analysis and objective setting in the adult migrant education program, Sydney, NSW, Adult Migration Education Services.

[4] Brunton, M. (2009). An account of ESP - with possible future directions. English for Specific Purposes Issue 3 (24), Volume 8. Retrieved from http://www.esp-world.info/Articles_24/An\%20account\%20of\%20ESP.pdf [last search date: 22 September, 2011]

[5] Carter, D. (1983). Some propositions about ESP. The ESP Journal, 2, 131-137.

[6] Donmall, A. (ed). (1985). Language awareness, London: CILT.

[7] Dudley-Evans, T., \& M. J. St. John. (1998). Developments in English for specific purposes: A multi-disciplinary approach. Cambridge, Cambridge University Press.

[8] Fairclough, N. (ed).(1992). Critical language awareness, London: Harlow. 
[9] Ferro, M.J. \& A.S. Carvalho. (2009). Language awareness and ESP responsiveness: teaching ESP to business students. Proceedings of the 8th International AELFE conference. La Laguna (Tenerife). Servicio de Publicaciones Universidad de la Laguna.

[10] Gardner, R. (1980). On the validity of affective variables in second language acquisition: conceptual, contextual and statistical considerations. Language Learning 30, 255-270.

[11] Gardner, R. (1985). Social Psychology and Second Language Learning. The Role of Attitudes and Motivation. London: Edward Arnold.

[12] Gatehouse, K. (2001). Key issues in English for Specific purposes (ESP) curriculum development. Internet TESL Journal, Vol VII, No. 10. Retrieved online: http://iteslj.org/Articles/Gatehouse-ESP.html [last search date: 22 September, 2011]

[13] González Ardeo, J. M. (2003). Attitude towards English and ESP acquisition as an L2 or L3 at university. Ibérica 6, 109-133.

[14] Graham, J. G. \& R. S. Beardsley. (1986). English for specific purposes: Content language, and communication in a pharmacy course model. TESOL Quarterly, 20.2, 227-245.

[15] Graves, K. (2000). Designing Language Courses: A guide for teachers. Heinle and Heinle.

[16] Hutchinson, T. \& A. Waters. (1987). English for specific purposes: A learning-centered approach. Cambridge, Cambridge University Press.

[17] James, C. and P. Garrett (eds.). (1991). Language awareness in the classroom. London: Longman.

[18] Jiajing, G. (2007). Designing an ESP course for Chinese university students of business. Asian ESP Journal. 3.1. Retrieved online: http://www.asian-espjournal.com/April_2007_gj.php [last search date: 22 September, 2011]

[19] Kaur, S. (2007). ESP course design: Matching learner needs to aims. ESP World. 1.14, Vol 6. Retrieved online: http://www.espworld.info/Articles_14/DESIGNING\%20ESP\%20COURSES.htm [last search date: 22 September, 2011]

[20] Lorenzo, F. (2005). Teaching English for specific purposes. UsingEnglish.com. Retrieved online: http://www.usingenglish.com/teachers/articles/teaching-english-forspecific-purposes-esp.html [last search date: 22 September, 2011]

[21] Miller, L. (2007). Issues in lecturing in a second language: lecturer's behaviour and students' perceptions. Studies in Higher Education, 32.6, 747-760.

[22] Mohan, B. A. (1986). Language and content. Reading, MA, Addison-Wesley.

[23] Nunan, D. (1988). The learner centred curriculum. Cambridge, Cambridge University Press.

[24] Oxford, R. \& J. Shearing. (1996). Language learning motivation in a new key. In R. Oxford (ed.), Language Learning Motivation: Pathways to the New Century, 121-144. Honolulu: University of Hawaii Press.

[25] Peacock, M. (1998). Exploring the gap between teachers' and learners' beliefs about 'useful' activities for EFL, International Journal of Applied Linguistics, 8.2, 233-250.

[26] Ramsden, P. (2003). Learning to teach in higher education. New York: Routledge.

[27] Richards, J. (2001). Curriculum development in language teaching. Cambridge, Cambridge University Press.

[28] Schmidt, R. W. (1990). The role of consciousness in second language learning. Applied Linguistics 11.2, $129-158$.

[29] Svalberg, Agneta M-L. (2007). Language awareness and language learning. Language Teaching Vol.40, 287-308, Cambridge University Press.

[30] Thornbury, S. (1997) Reformulation and reconstruction: tasks that promote noticing. English Language Teaching Journal, 51.4, 326-335.

[31] West, R. (1997). Needs analysis: state of the art. In R. Howard and G. Brown (Eds.), Teacher education for LSP, 68-79. Clevedon, England, Multilingual Matters.

Nuria Edo Marzá was born in Spain in 1980. She received her PhD in English Philology from University Jaume I (Castellón, Spain) in 2008. She also received a master's degree in Terminology in 2009 from Universitat Pompeu Fabra (Barcelona, Spain). She is currently a professor of the English Studies Department at Universitat Jaume I (Castellón, Spain) but she also worked as a lecturer and researcher from 2009 to 2011 at University of Valencia (Spain).

She is the author of the book The Specialised Lexicographical Approach: a Step Further in Specialised Dictionary Making (2009) Peter Lang, and of the health-related volumes Spoken English for the medical professional (2011), English for Patient and nonclinical Hospital Staff (2011) and English for Pharmacists (2011), all of them published byEditorial Formación Alcalá. She is also the author of the research paper "The generation of active entries in a specialised, bilingual, corpus-based dictionary of the ceramics industry: what to include, why and how" (2009). Ibérica, 18, 43-71.

Dr. Edo research interests include the fields of specialised languages, terminology, terminotics and specialised lexicography among others. 